RESEARCH ETHICS

\title{
Pharmacogenetics, ethical issues: review of the Nuffield Council on Bioethics Report
}

\section{O P Corrigan}

J Med Ethics 2005;31:144-148. doi: 10.1136/jme.2004.007229

In September this year the Nuffield Council on Bioethics held a meeting to disclose and discuss the main findings of their newly published report on the ethical issues associated with developments in pharmacogenetics research. The basics of pharmacogenetics science is briefly outlined, and then the extent to which the report was successful in addressing (or at least highlighting) the attendant social, ethical, and policy implications of pharmacogenetics research is evaluated.

Correspondence to: Dr O P Corrigan, Centre for Family Research and Cambridge Genetics Knowledge Park, Faculty of Social and Political Sciences, University of Cambridge, Free School Lane, Cambridge, B2 3RF, UK; opc22@cam.ac.uk

Received 13 July 2004 Accepted for publication 27 July 2004
G reat things are expected from the rapidly developing field of pharmacogenetics, yet its re-mergence during the late 1990s has been accompanied by concerns about its social and ethical implications. ${ }^{1-6}$ The Nuffield Council on Bioethics report, Pharmacogenetics: Ethical Issues, makes an important and timely contribution to this debate. ${ }^{7}$ The Nuffield council's working party, chaired by philosopher Peter Lipton, was composed of nine senior academics from the humanities, social sciences, and medical sciences. Established in September 2002, the working party engaged in fact finding sessions with experts from the sciences and the pharmaceutical industry (five sessions in London), and held a consultation with the public (84 responses from 15 countries to the exploratory document), published in September 2003. As we are informed in the report, the terms of reference of the working party were "to explore what pharmacogenetics offers now and is likely to offer in the near future; to consider ethical issues specifically raised by pharmacogenetics" (Nuffield Council on Bioethics, ${ }^{7}$ p 9) and "to consider the implications for the provision of health care" (Nuffield Council on Bioethics, ${ }^{7} \mathrm{p}$ xi). Although at 69 pages it is one of the briefest of the council's reports of this kind, it is nevertheless wide ranging and examines pharmacogenetics in terms of its scientific background in the context of research and development of new medicines, as well as anticipating the regulatory and public policy implications and ethical issues that could arise when and if pharmacogenetics emerges into everyday medical practice. The report is to be commended for being comprehensive in scope, for raising a number of important points for discussion, and for making practical policy recommendations. Due perhaps in part to its brevity, the report does, however, fail to explore in preparation for drafting of the final report some issues in sufficient depth. Despite its aforementioned brief, the report concentrates too much on speculative future focused ethical issues, failing to give adequate attention to the important issues that are currently arising, particularly with regards to the large scale collection and storage of DNA from patients currently taking part in clinical drug trials. Also, while the report's authors are right to suggest that more caution and consideration is needed in accepting hitherto "optimistic" claims about the potential benefits of pharmacogenetics, they do not go far enough in this regard and fail to analyse the political and economic context surrounding the much publicised hype surrounding pharmacogenetics research and development. Given these shortcomings, rather than simply present a critical summary I shall instead turn my attention to the aforementioned problems. I begin by placing pharmacogenetics in its social and political context in order to comprehend the current hype and thereby provide a better grounding and analysis of the ethical issues.

\section{THE POLITICAL, ECONOMIC, AND SCIENTIFIC BACKGROUND}

Scientists understand that "normal" genetic variation in the population can affect an individual's ability to respond effectively to a medicine. This sometimes results in a patient suffering from an adverse drug reaction or a poor therapeutic response to the medication. The link between genetic variation and drug metabolism was first identified in the late 1950s-the term "pharmacogenetics" was used to signify the relationship between genetic make up and drug therapy. ${ }^{8}$ Pharmacogenetics can best be defined then as an area of research and a set of technologies aimed at addressing problems of variation in drug effect, by linking drug response to individual genetic variation. ${ }^{10}$ Until recently, pharmacogenetics has had limited impact on the pharmaceutical industry's development of new medicines. New technological advances in genomics, stemming for the human genome project, have, however, made possible the rapid identification of many of the individual genes that code for proteins involved in drug absorption, distribution, metabolism, and elimination. ${ }^{11}$ The expectations are that developments in this field will eventually lead to a move away from a "one size fits all" approach in the prescribing and development of new drugs, to the tailoring of new medicines to an individual's genetic

Abbreviations: $A D R$, adverse drug reaction 
profile. ${ }^{12}$ Indeed, the prospect of "personalised medicines" or "designer drugs" is one that is often alluded to in the promotion of such endeavours.

As sociologists of science and technology have demonstrated, the development of any scientific field is not merely a scientific endeavour, because the ways in which the sciences develop are shaped as much by social, political, and economic influences as scientific ones. Although the boundaries between economics, politics, and science have always been rather blurred, the new genetics and the upsurge of biotechnology have increased this boundary blurring. This raises questions for the ethical assessment of a scientific development, not least because the benefits and risks are difficult to ascertain. Any assessment of the moral worth of developments in pharmacogenetics should therefore involve a careful examination of the political and economic terrain and pay particular attention to the potential for hype. In relation the study of ethical issues involved in genetic testing, Onora O'Neill urges that: "... bioethical debate will have to become more political, and to take fuller cognisance of the realities of the contemporary world, its technologies and institutional possibilities". ${ }^{13}$ In particular, it is important to focus on factors driving the pharmacogenetic research programme forward and to comprehend the hype that surrounds this field.

One of the key drivers of pharmacogenetics is the commercial sector, especially large pharmaceutical companies (which are responsible for developing and marketing new drugs) and small biotech companies that are involved in providing test kits and technological innovations that support the pharmaceutical industry in their research endeavours. A recent survey ${ }^{14}$ reports that these two industry sectors are currently engaged in commercial plans to exploit the promise of pharmacogenetics, having already committed considerable investment. Many large pharmaceutical companies have made alliances with small biotech companies-for example, in 1997 the biotech company Genset and the pharmaceutical company Abbott Laboratories entered into an exclusive \$20 million alliance to analyse variations in patient responses to particular drug therapies. ${ }^{15}$ Some sectors of the pharmaceutical industry remain sceptical and are not persuaded by the idea that pharmacogenetics will bring increased profits. Instead, they are concerned that such an initiative based on niche products may result in market segmentation, increased research and development costs, ${ }^{16}$ and reduced profits. ${ }^{10}$ Nevertheless, there remains a significant swathe of opinion within the industry that such developments will bring significant economic gains for corporations, providing them with a competitive advantage in the marketplace as a result of increased sales of "personalised medicines" and reduced costs from greater efficiencies in drug development. ${ }^{17}$ GlaxoSmithKline, one of the world's largest pharmaceutical companies, has played a prominent role in promoting pharmacogenetics, with company scientists producing a number of scientific papers in high profile science and medical journals urging the uptake of pharmacogenetics. ${ }^{11}{ }^{17-20}$ Many other major pharmaceutical companies are now investing heavily in pharmacogenetics, ${ }^{21}$ and indeed, as I have already suggested, the commercial sector, led by major pharmaceutical companies, is the main driving force behind the "push" for continued research into, and implementation of, this technology in the UK and globally.

The UK government too expects great health care benefits to be derived from pharmacogenetics. In their white paper, Our Inheritance, Our Future: Realising the Potential of Genetics in the NHS, the Department of Health asserted that "the greatest impact on health care in the shorter term is likely to come from pharmacogenetics". ${ }^{22}$ A positive valuation of new breakthroughs in drug development, and in particular pharmacogenetics, appears to come from the highest levels of government - the Department of Health is being urged by the prime minister Tony Blair to commit to ensuring that "the future of the UK pharmaceutical industry is even brighter" ${ }^{23}$ The UK pharmaceutical industry is seen as vital to our "knowledge economy" and as such, developments in pharmacogenetics need to be understood as having as much to do with wealth creation as health promotion. It must also be understood that when financial stakes are high, hyperbole is often present.

As Nik Brown notes: "[V]arious areas of technological innovation become saturated with stratospherically high expectations of immanent and revolutionary change.... Biotech is no exception and is today synonymous with the language and imagery of futuristic breakthroughs. The whole area is literally spilling over with heated aspirations, promises, expectations, hopes, desires, and imaginings." 24

Although we have yet to see a crash in investment, as tends to occur when the promises made about a new science do not materialise or are not translated into marketable products, in many ways the current hype surrounding pharmacogenetics resembles that which surrounded gene therapy trials in the early 1990s. While there is still progress being made in this field, 15 years on there are still no working gene therapies on the market. The fantastic hopes that arose during gene therapy's infancy led to an investor gold rush, but the failure to rapidly realise profitable products resulted in investor anxiety and the collapse of numerous small biotech companies, as well as the withdrawal of many large pharmaceutical companies from gene therapy partnerships. Furthermore, gene therapies are still associated with a high degree of risk to patients: the recent death of a patient following gene therapy in the US resulted in a temporary cessation of these trials..$^{25}$

\section{RISKS AND BENEFITS}

The hoped for benefits of pharmacogenetics being promised to patients are that drugs prescribed in the future will be more effective and far less likely to induce adverse drug reactions (ADRs). The issue of ADRs has become increasingly salient and politicised following large scale studies examining the worryingly high prevalence of serious ADRs in the UK and the US. ${ }^{26} 27$ While the issue of serious drug induced reactions is something that in the past the pharmaceutical industry has been keen to play down, such incidences are now being highlighted as rationales for the promotion of pharmacogenetics. The contribution that pharmacogenetics could make in the reduction of adverse drug reactions has thus added further moral weight to the need to encourage this developing scientific endeavour.

The Nuffield Council's report acknowledges the overly optimistic timeline being suggested by protagonists, and argues for the careful examination of such claims. The report's authors note that there are currently very few applications of pharmacogenetics testing, and that there could well be serious delays in bringing this technology to the clinic. The report also states that the promise of personalised medicine is misleading and that rather than pharmacogenetics resulting in tailor made or personalised treatment as originally promised, "pharmacogenetic tests are likely to generate probabilistic medicine of varying degrees" (Nuffield Council on Bioethics, ${ }^{7}$ p 6). As the report rightly claims, instead of finding the "right drug for the right person", pharmacogenetic testing might only be able to suggest a particular drug for genetically defined groups. The report's authors also point to the attendant social and economic concerns, suggesting that the stratification of the population into genetic subgroups may mean that the costs of developing 
new medicines for small populations could be prohibitively expensive for pharmaceutical companies, with the result that effective therapies might not be developed for certain "orphan" groups.

Notwithstanding these insightful comments, the report does not in my opinion go far enough in acknowledging the scientific uncertainties of pharmacogenetics research. David Melzer and his research team ${ }^{28}$ conducted an in depth study into the policy implications of pharmacogenetics, and have shown that expert opinion is less optimistic as the complexities of gene/gene, and gene/environment interaction have become more apparent. A single genetic variation-for example, is not highly predictive of drug response. ${ }^{29}$ Even though a genetic variation may mean that a person does not produce a protein known to be required for drug metabolism, the drug may nevertheless work because other genes, pathways, and environmental factors are involved. When we look at the history of drug discovery we see that scientific evidence has been required to demonstrate that a drug works, but not how it works. It seems therefore, that the process of identifying genes which have a direct impact on drug effect is proving more difficult than expected.

Furthermore, even if these problems are overcome, the likelihood that pharmacogenetics can make a substantial impact on the reduction of the incidence of serious adverse drug reactions is also highly debatable. The report accepts the premise that pharmacogenetics will be an effective mechanism for reducing the incidence of adverse drug reactions, a claim about benefit that has underpinned much of the ethical impetus for pharmacogenetics research. Although the report acknowledges that ADRs can be caused by various factors other than genetic variation, it fails to mention the importance of other variables such as age $e^{30}$ or $\operatorname{sex}^{,{ }^{31}}$ to name only two. A recent study of ADRs in the elderly has shown that serious ADRs are predictable, and that more than two thirds of ADRs are therefore preventable. ${ }^{32}$ In other words, the problem of ADRs could be radically reduced if other nongenetic based prescribing interventions were adopted. This is not to say that pharmacogenetics has no role to play. The dose variation response of the drug warfarin-for example, has been show to be determined by a combination of genetic, clinical, and demographic factors; the subsequent use of an algorithm based on these factors more than halved the risk of adverse drug reactions. ${ }^{33}$ Pharmacogenetics is not a panacea, and the benefits arising from pharmacogenetics (purported by industry advocates and largely accepted by the report's authors) have arguably been exaggerated. ${ }^{34}$

The report has some further shortcomings, in so far as it fails to adequately address the ethical problems arising with the collection and storage of DNA samples during clinical drug trials. Given that so many of the ethical problems highlighted by the Report are based on future scenarios, the manifestation of which will ultimately depend upon scientific progress and the success of pharmacogenetics, it is very disappointing to find that the report falls short of adequately addressing the current issues with reference to DNA collection in pharmaceutical company sponsored clinical drug trials. In particular, the report fails to acknowledge the extent of the current routine practice of collecting and storing DNA samples and data during clinical drug trials. Research currently being undertaken by social scientists, such as myself, suggests that thousands of DNA samples are being collected during clinical drug trials and stored by the industry daily, and indeed most pharmaceutical company sponsored clinical drug trials now involve the collection of samples as routine. ${ }^{35}$ The report's failure to reveal details of the current ongoing practice is perhaps not surprising given that there are very few hard facts about the number of samples collected and stored by the pharmaceutical industry (which is notoriously secretive about such activities. ${ }^{36}$ It is, however, disappointing that the report's authors have not considered the parallel ethical issues in the collection and banking of DNA samples for genetic research. Such issues have given rise to sustained academic and public debate about appropriate policy for the collection and long term storage of DNA, especially with regards to consent and confidentiality, ownership, access, and control of such data. ${ }^{37-39}$ It is a shame that the report failed to deliberate on some of these well discussed issues. In particular, the issues of commercial ownership and access of DNA banked in large scale population databases raise ethical concerns over control, ownership, and profit sharing. ${ }^{40}$ Issues of intellectual property rights and the granting of patents in particular have confronted policy makers with severe challenges. In the case of the widely criticised Icelandic Health Sector Database, DeCode (the company with exclusive rights to use of the database) only belatedly agreed to give the Icelandic health authorities a share of its profits. ${ }^{41}$

Blood samples and data that are donated for genetic testing purposes during the pharmacogenetic part of a clinical trial represent a valuable resource in the production of genetic based drug developments. Patients agreeing to donate DNA samples for pharmacogenetics are asked to sign a form acknowledging that the sponsoring pharmaceutical company has property rights over the samples and data collected. Furthermore, when asked to consent to long term future research and storage of their samples, patients are waiving any future control over the kinds of research in which their samples may be used. Should individuals not wish to consent to this, they are informed that their sample will be removed and destroyed. As Graham Lewis indicates, however, ${ }^{36}$ given the complex arrangements concerning storage of these samples by third party companies (many of whom are currently undergoing mergers), this endeavour may prove difficult and without effective oversight it may be hard to ascertain whether companies are adhering to these promises. Unlike public genetic databases, pharmaceutical company genetic databases are not subject to the same governance mechanisms that ensure transparency and adequate oversight. As already mentioned, pharmaceutical companies are under no compulsion to publicly disclose the numbers and whereabouts of samples being stored.

\section{CONSENT, PRIVACY, AND CONFIDENTIALITY}

The report briefly discusses issues relating to consent, privacy, and confidentiality but again fails to get to the heart of the matter. In pharmacogenetic studies, patients are asked to consent to three separate aspects of research: the main clinical drug trial; research involving a specific genetic test related to a drug effect; and unspecified genetic tests to be used in future pharmacogenetics research. In doing so they give the sponsoring pharmaceutical company permission to link genetic research on their blood sample to personal medical information, such as details of their medical condition and family history. Given evidence of the inability of patients who have decided to take part in clinical trials to comprehend information about trial procedures or to recall information about potential risks, ${ }^{42-44}$ it is likely that patients entering into pharmacogenomics related trials will not have given careful consideration to all potential risks and benefits of this additional research. While the report acknowledges that consent seldom lives up to the ideal, I would suggest that the limits of consent for pharmacogenomics studies are being transgressed. Patients who already feel overburdened with information and anxiety, and in a weak position when it comes to making independent decisions, may be exploited in this situation. Although in conventional clinical drug trials patients are subjected to additional risks over and above 
conventional therapy, patients have at least the possibility of benefiting either from the comparative drug being tested or from the trial drug (or the placebo effect). By contrast, there is no direct benefit to the patient in the pharmacogenetics study and thus compromises in the consent process cannot be offset against potential therapeutic benefit. ${ }^{45}$ The issues to do with broad consent that allows the indefinite storage and future as yet unspecified research are particularly problematic. The report's authors suggest that in these cases the consent of the patient is acquired some time after the initial consent to the trial and consent to the collection of DNA for pharmacogenetics testing related to the trial has been sought. I suggest, however, that this does not go far enough: because the samples may end up being deployed for research unrelated to the initial trial, these should not be collected on the back of the trial itself. Interestingly, GlaxoSmithKline has recently changed its policy and moved away from broadbased consent, and now collect samples during clinical trials for use in drug response research only and not for disease gene research. Furthermore, as I have mentioned, the latter sample collections are defined as "non-therapeutic", are thus subject to different ethical considerations, and in line with other non-therapeutic research conducted by the industry should be subject to the requirement to offer subjects financial compensation for taking part in research. I am not suggesting that such research should not be carried out, as future research use may yield important health related societal benefits, but that collections of DNA and health related information should be carried out separately. Indeed, in many ways the collection of DNA for national genetic databases such as the proposed UK Biobank will serve this purpose, and of course pharmaceutical companies are likely to pay for access to these samples. Finally, if as the report suggests informed consent is a rather weak ethical protection, it is all the more important that other mechanisms such as independent oversight of the DNA banks be in place to offer protection to prospective patients. The report, in suggesting that research ethics committees be responsible for ensuring patient welfare in the context of research, has failed to appreciate the limited powers of oversight in monitoring ongoing studies. Research ethics committees have no powers of audit and there is no independent oversight or indeed public knowledge of industry owned data and tissue banks.

\section{CONCLUSION}

The Nuffield Council on Bioethics' report on the ethics of pharmacogenomics makes a valuable contribution to ongoing academic and public discussions about new developments in biomedical research and technologies. While, however, the report usefully highlights some areas in need of further ethical reflection and policy response, and makes important recommendations for the implementation of oversight and regulatory mechanisms to protect against some of the more egregious harms of pharmacogenetics, it simply does not go far enough in putting this new technology into the broader context of pharmaceutical research and drug development.

\section{ACKNOWLEDGEMENTS}

I would like to express my thanks to the Wellcome Trust for sponsoring my own research in this area and to Bryn Williams-Jones for his helpful comments.

The Wellcome Trust sponsored my research in this area.

Competing interests: none declared

\section{REFERENCES}

1 Buchanan A, Califano A, Kahn J, et al. Pharmacogenetics: ethical issues and policy options. Kennedy Inst Ethics J 2002;12:1-15.
2 Greely HT. Pharmacogenomics: promise, prospects, and potential problems. Lahey Clin Med Ethics News 2002;9:1-2, 8.

3 Issa AM. Clinical impact of pharmacogenomics. Trends Pharmacol Sci 2000;21:247-9.

4 Moldrup C. Ethical, social, and legal implications of pharmacogenomics: a critical review. Community Genet 2001;4:204-14.

5 Spallone P, Wilkie T. The research agenda in pharmacogenetics and biological sample collections - a view from the Wellcome Trust. New Genet Soc 2000;19:193-205.

6 Freund CL, Wilfond BS. Emerging ethical issues in pharmacogenomics: from research to clinical practice. Am J Pharmacogenomics 2002;2:273-81.

7 Nuffield Council on Bioethics. Pharmacogenetics: ethical issues. London: Nuffield Council on Bioethics, 2003.

8 Bullock PL. Pharmacogenetics and its impact on drug development. Drug Benefit Trends 1999;11:53-4.

9 Moldrup C. When pharmacogenomics goes public. New Genet Soc 2002;21:29-37.

10 Snedden $\mathbf{R}$. The challenge of pharmacogenetics and pharmacogenomics. New Genet Soc 2000; 19:145-64.

11 Roses AD. Pharmacogenetics and future drug development and delivery. Lancet 2000;355:1358-61.

12 Evans WE. Pharmacogenomics: marshalling the human genome to individualise drug therapy. Gut 2003;52(suppl 2):10-18S.

13 O'Neill O. Informed consent and genetic information. Stud Hist Philos Sci Part C 2001;32:689-704 at 702 .

14 Hedgecoe A, Martin P. The drugs don't work: expectations and the shaping of pharmacogenetics. Soc Stud Sci 2003;33:327-64.

15 Anon. Pharmacogenomics. Nat biotechnol 2000;18(suppl):IT40-IT2S.

16 Danzon P, Towse A. The economics of gene therapy and of pharmacogenetics. Value Health 2002;5:5-13.

17 McCarthy A. Pharmacogenetics: implications for drug development, patients, and society. New Genet Soc 2000;19:135-64.

18 Roses AD. Pharmacogenetics and the practice of medicine. Nature 2000;405:857-65.

19 Roses AD. The human medicine project has started: place your bets now. Drug Discov Today 2001;6:282-4

20 Roses AD. Genome-based pharmacogenetics and the pharmaceutical industry. Nat Rev Drug Discov 2002;1:541-9.

21 Bogdanovic S, Langlands B. Pharmacogenomics players. London: Financial Times, 1999.

22 Department of Health. Our inheritance, our future-realising the power of genetics in the NHS. London: Department of Health, 2003.

23 Pharmaceutical Industry Competitiveness Task Force. Value of the pharmaceutical industry to the UK economy. London: Department of Health, 2001 ; http:// www.advisorybodies.doh.gov.uk/pictf/index.htm\#tor (accessed 24 Jun 2004)

24 Brown N. Hope against hype-accountability in biopasts, presents, and futures. Sci Stud 2003;16:3-21.

25 Federal Drug Administration, National Institutes of Health. New initiatives to protect participants in gene therapy trials. HHS News, 2000 Mar 7 http:// www.fda.gov/bbs/topiccs/NEWS/NEW00717/html laccessed 2 Nov 2004).

26 Lazarou J, Pomeranz BH, Corey PN. Incidence of adverse drug reactions in hospitalized patients - a meta-analysis of prospective studies. JAMA 1998;279:1200-05.

27 Pirmohamed $M$, Breckenridge $A M$, Kitteringham NR, et al. Fortnightly review: adverse drug reactions. BMJ 1998;316:1295-8.

28 Melzer D, Raven A, Detmer DE, et al. My very own medicine: what must I know? Information policy for pharmacogenetics. London: Wellcome Trust, 2003.

29 Johnson J. Drug target pharmacogenomics: an overview. Am J Pharmacogenomics 2001;1:271-81.

30 Atkin PA, Shenfield GM. Medication-related adverse reactions and the elderly: a literature review. Adverse Drug React Toxicol Rev 1995; 14:175-91.

31 Yonkers K, Kando J, Cole J, et al. Gender differences in pharmacokinetics and pharmacodynamics of psychotropic medication. Am J Psychiatry 1993; 150:678-9

32 Pirmohamed M, James S, Meakin S, et al. Adverse drug reactions as cause of admission to hospital: prospective analysis of 18820 patients. BMJ 2004;329:15-19.

33 Gag B, Eby C, Milligan P, et al. Use of pharmacogenetics and clinical factors to predict the maintenance dose of warfarin. Thromb Haemost 2004:91:87-94.

34 Williams-Jones B, Corrigan OP. Rhetoric and hype: where's the "ethics" in pharmacogenomics? Am J Pharmacogenomics 2003;3:375-83.

35 Corrigan OP. Informed consent: the contradictory ethical safeguards in pharmacogenetics. In: Tutton R, Corrigan OP, eds. Genetic databases: socioethical issues in the collection and use of DNA. London: Routledge, 2004:78-96.

36 Lewis $\mathbf{G}$. Tissue collection and the pharmaceutical industry: investigating corporate biobanks. In: Tutton R, Corrigan O, eds. Genetic databases: socioethical issues in the collection and use of DNA. London: Routledge, 2004.

37 Lavori PW, Krause-Steinrauf H, Brophy M, et al. Principles, organization, and operation of a DNA bank for clinical trials: ${ }^{*} 1$ : a Department of Veterans Affairs cooperative study. Control Clin Trials 2002;23(suppl):222-39S.

38 Knoppers BM. Human genetic material: commodity or gift? In: Weir RF, ed. Stored tissues samples: ethical, legal, and public policy implications. lowa: University of lowa Press, 1998:226-35.

39 Martin P, Kaye J. The use of large biological sample collections in genetics research: issues for public policy. New Genet Soc 2000; 19:165-91. 
40 Marks AD, Steinberg KK. The ethics of access to online genetic databases: private or public? Am J Pharmacogenomics 2002;2:207-12.

41 Merz J, Sankar P. DNA banking: an empirical study of a proposed consen form. In: Weir RF, ed. Stored tissue samples: ethical, legal and public policy implications. lowa: University of lowa Press, 1998:198-225.

42 Corrigan OP. Empty ethics: the problem with informed consent. Sociology Health Illn 2003;25:768-92.
43 Cassileth B, Zupkis R, Sutton-Smith K, et al. Informed consent-why are its goals imperfectly realized? N Engl J Med 1980;302:896-900.

44 Snowdon C, Garcia J, Elbourne D. Making sense of randomisation: responses of parents of critically ill babies to random allocation of treatment in a clinical trial. Soc Sci Med 1997:45:1337-55.

45 Corrigan OP, Williams-Jones B. Pharmacogenetics: the bioethical problem of DNA investment banking. Stud Hist Philos Sci Part C. In press.

\section{Clinical Evidence - Call for contributors}

Clinical Evidence is a regularly updated evidence-based journal available worldwide both as a paper version and on the internet. Clinical Evidence needs to recruit a number of new contributors. Contributors are healthcare professionals or epidemiologists with experience in evidence-based medicine and the ability to write in a concise and structured way.

Areas for which we are currently seeking authors:

- Child health: nocturnal enuresis

- Eye disorders: bacterial conjunctivitis

- Male health: prostate cancer (metastatic)

- Women's health: pre-menstrual syndrome; pyelonephritis in non-pregnant women

However, we are always looking for others, so do not let this list discourage you.

\section{Being a contributor involves:}

- Selecting from a validated, screened search (performed by in-house Information Specialists) epidemiologically sound studies for inclusion.

- Documenting your decisions about which studies to include on an inclusion and exclusion form, which we keep on file.

- Writing the text to a highly structured template (about 1500-3000 words), using evidence from the final studies chosen, within 8-10 weeks of receiving the literature search.

- Working with Clinical Evidence editors to ensure that the final text meets epidemiological and style standards.

- Updating the text every six months using any new, sound evidence that becomes available. The Clinical Evidence in-house team will conduct the searches for contributors; your task is simply to filter out high quality studies and incorporate them in the existing text.

- To expand the topic to include a new question about once every 12-18 months.

If you would like to become a contributor for Clinical Evidence or require more information about what this involves please send your contact details and a copy of your CV, clearly stating the clinical area you are interested in, to Klara Brunnhuber (kbrunnhuber@ bmigroup.com).

\section{Call for peer reviewers}

Clinical Evidence also needs to recruit a number of new peer reviewers specifically with an interest in the clinical areas stated above, and also others related to general practice. Peer reviewers are healthcare professionals or epidemiologists with experience in evidence-based medicine. As a peer reviewer you would be asked for your views on the clinical relevance, validity, and accessibility of specific topics within the journal, and their usefulness to the intended audience (international generalists and healthcare professionals, possibly with limited statistical knowledge). Topics are usually 1500-3000 words in length and we would ask you to review between 2-5 topics per year. The peer review process takes place throughout the year, and our turnaround time for each review is ideally 10-14 days.

If you are interested in becoming a peer reviewer for Clinical Evidence, please complete the peer review questionnaire at www.clinicalevidence.com or contact Klara Brunnhuber (kbrunnhuber@bmigroup.com). 